\title{
Evaluation of lubrication performance of crank pin bearing in a marine diesel engine
}

\author{
Suk Man MOON ${ }^{1}$, Yong Joo CHO ${ }^{1}$, Tae Wan $\mathrm{KIM}^{2, *}$ \\ ${ }^{1}$ School of Mechanical Engineering, Pusan National University, San 30 Changjeon-Dong, Kumjeong-Gu, Busan 609-735, Republic of Korea \\ ${ }^{2}$ Department of Mechanical Engineering, Pukyong National University, San 100 Yongdang-Dong, Nam-Gu, Busan 608-739, Republic of Korea \\ Received: 14 May 2017 / Revised: 21 August 2017 / Accepted: 01 November 2017 \\ (C) The author(s) 2017. This article is published with open access at Springerlink.com
}

\begin{abstract}
In this study, the lubrication performance of the crank pin bearing in a marine two-stroke diesel engine is evaluated to investigate the adhesional failure on the crank pin bearing. A numerical algorithm for the lubrication analysis considering motion analysis of the crank pin system is developed. The film pressure and thickness for three clearances and three lubricant temperatures are calculated. The results show that the lubricant temperature has a higher effect on film thickness than clearance. In terms of the film parameter, the operating condition that can result in solid-solid contact is investigated. We also suggest the desirable operating conditions of clearance and lubricant temperature to prevent the solid-solid contact.
\end{abstract}

Keywords: crank pin bearing; film thickness; lubricant film parameter; diesel engine

\section{Introduction}

The wear caused by insufficient lubrication is the most general cause of endurance life issues. An absence of lubrication in the journal-bearing system leads to bearing seizure, and normally, to total destruction of the part. The motivation of this study is an adhesional failure observed on the crank pin in a marine twostroke diesel engine, as shown in Fig. 1. Insufficient lubrication caused by factors such as a machining error in the manufacture of the crank pin and the bearing leads to solid-solid contact between the crank pin and the bearing, which results in adhesional wear. Prolonged operation under such conditions also results in complete destruction of the part. The crank pin bearing which connects the connecting rod and crank arm, converting a reciprocating motion into a rotary motion plays an important role in a marine engine. Predicting the lubrication state of the crank pin bearing and the possible early bearing damage can ensure the normal operation of a marine diesel engine.

The investigation of the minimum oil film thickness in the engine bearing is important to prevent the above problems, and have been conducted in many studies [1-5]. The simulation models are classified as the methods based on hydrodynamic, elastohydrodynamic (EHD), and thermo-elasto-hydrodynamic lubrication theories [6-10]. Bukovnick et al. [11] compared the different models for the simulation of non-stationary response of the journal bearings used in combustion engines. Recently, coupling simulations between EHD and nonlinear multi-body dynamics (MBD) have been conducted for dynamically-loaded
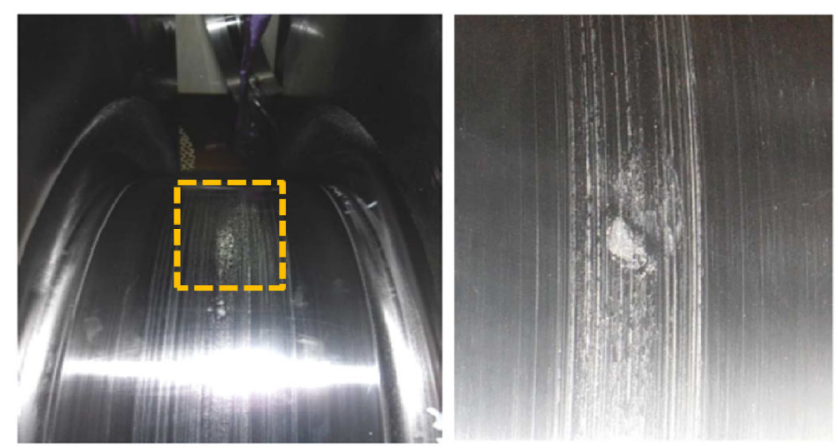

Fig. 1 Failure of crank pin.

* Corresponding author: Tae Wan KIM, E-mail: tw0826@pknu.ac.kr 
bearings of a marine diesel engine. $\mathrm{Wu}$ et al. [12] developed an EHD coupling analysis model for the main bearing lubrication of a marine diesel engine using AVL Excite software, and explored the main bearing's vertical load, orbital path and minimum oil film thickness.

In this study, a lubrication analysis was conducted to reveal the cause of adhesional failure on the crank pin bearing of a marine two-stroke diesel engine. We developed a numerical algorithm for the hydrodynamic lubrication analysis coupling with the motion analysis of the piston-connecting rod-crank arm system. The lubrication performance, including film pressure and thickness, were investigated for three clearances and three lubricant temperatures. The calculated film thickness was compared with the measured surface roughnesses of the crank pin journal and the bearing.

\section{Analysis}

\subsection{Motion analysis of crank pin}

Figure 2 shows a schematic of crank pin motion with the piston position. The bearing loads, which include the radial force $F_{\mathrm{R}}$ and the tangential force $F_{\mathrm{T}}$, and the relative velocity between the crank arm and connecting rod can be obtained from the force equilibrium equations.

The angular range of the crank arm angle $\alpha$, the angular velocity of the crank arm $\omega$, and the angular acceleration of the crank arm $\ddot{\alpha}$ are expressed as

$$
\begin{gathered}
\alpha=0-2 \pi \\
\omega(=\dot{\alpha})=\frac{2 \pi \cdot n}{60} \\
\ddot{\alpha}=0
\end{gathered}
$$

where $n$ is the engine speed. From the relation of the crank arm and connecting rod in Fig. 2(b), the angle $\beta$, angular velocity $\dot{\beta}$, and angular acceleration $\ddot{\beta}$ of the connecting rod can be written as

$$
\begin{gathered}
\beta=\cos ^{-1}\left(\frac{r_{\mathrm{ca}}}{r_{\mathrm{cr}}} \sin \alpha\right) \\
\dot{\beta}=-\frac{r_{\mathrm{ca}} \cos \alpha}{r_{\mathrm{cr}} \sin \beta} \omega
\end{gathered}
$$$$
\ddot{\beta}=\frac{r_{\mathrm{ca}} \omega^{2}}{r_{\mathrm{cr}} \sin \beta}\left\{\sin \alpha-\left(\frac{r_{\mathrm{ca}}}{r_{\mathrm{cr}}}\right) \frac{\cos ^{2} \alpha \cos \beta}{\sin ^{2} \beta}\right\}
$$

where $r_{\mathrm{ca}}$ and $r_{\mathrm{cr}}$ are the lengths of the crank arm and connecting rod, respectively. The equilibrium equations for the connecting rod in Fig. 2(c) are given as

$$
\sum F_{\mathrm{x}}=m_{\mathrm{c}} \vec{a}_{\mathrm{x}} ; F_{1 \mathrm{x}}-F_{2 \mathrm{x}}=m_{\mathrm{c}} \vec{a}_{\mathrm{x}}
$$

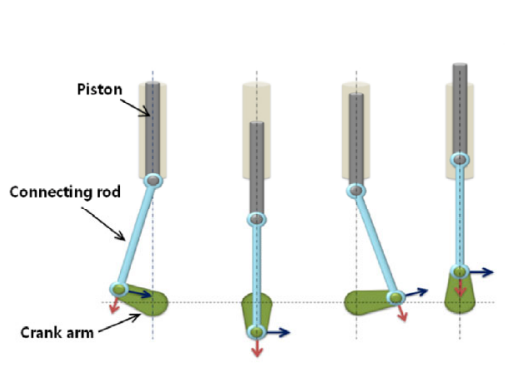

(a) Crank pin motion

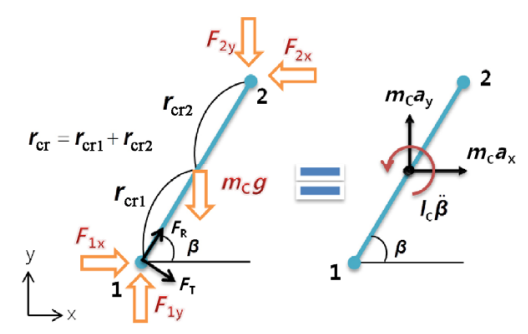

(c) Connecting rod

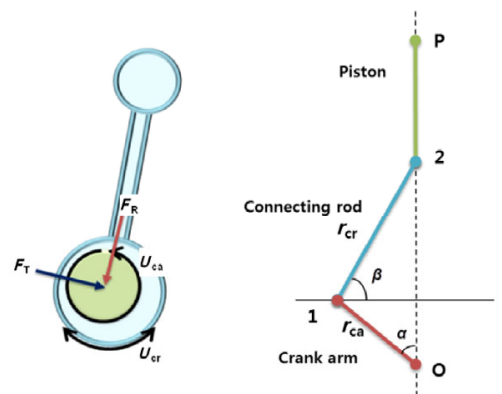

(b) Crank system schematic

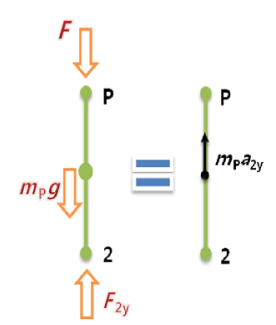

(d) Piston

Fig. 2 Schematic diagram of the crank pin motion and the force equilibrium for bearing loads and relative velocity. 


$$
\begin{gathered}
\sum F_{\mathrm{y}}=m_{\mathrm{c}} \vec{a}_{\mathrm{y}} ; F_{1 \mathrm{y}}-F_{2 \mathrm{y}}-m_{\mathrm{c}} g=m_{\mathrm{c}} \vec{a}_{y} \\
\sum M_{\mathrm{G}}=I_{\mathrm{c}} \ddot{\beta} ; F_{1 \mathrm{x}} \cdot r_{\mathrm{cr} 1} \sin \beta-F_{1 \mathrm{y}} \cdot r_{\mathrm{cr} 1} \cos \beta+F_{2 \mathrm{x}} \\
\cdot r_{\mathrm{cr} 2} \sin \beta-F_{2 \mathrm{y}} \cdot r_{\mathrm{cr} 2} \cos \beta=I_{\mathrm{c}} \ddot{\beta}
\end{gathered}
$$

where $m_{\mathrm{c}}$ is the mass of the connecting rod, $g$ is the acceleration of gravity, and $I_{\mathrm{c}}$ is the moment of inertia of the connecting rod. In addition, $\vec{a}_{x}$ and $\vec{a}_{y}$ are the accelerations at the center of mass, $F_{1 \mathrm{x}}$ and $F_{1 \mathrm{y}}$ are the reaction forces at point 1 , and $F_{2 x}$ and $F_{2 y}$ are the loaded forces at point 2 from the piston, in the $x$ and y directions, respectively. Here, assuming that $F_{2 x}$ is negligible because the piston is constrained in the $\mathrm{x}$ direction by the cylinder guide, $F_{2 y}$ can be derived from the equilibrium equation for the piston in Fig. 2(d) as

$$
\begin{aligned}
\sum F_{\mathrm{y}}= & m_{\mathrm{p}} a_{2 \mathrm{y}} ; F_{2 \mathrm{y}}=m_{\mathrm{p}}\left(-a_{1} \cos \alpha+r_{\mathrm{cr}}\right. \\
& \left.\cdot \ddot{\beta} \cos \beta-r_{\mathrm{cr}} \cdot \dot{\beta}^{2} \sin \beta\right)+m_{\mathrm{p}} g+F
\end{aligned}
$$

where $F$ is the force applied by the gas pressure, $m_{\mathrm{p}}$ is the mass of the piston, and $a_{1}$ is the acceleration at point 1. Combining Eq. (10) with Eqs. (7)-(9), the following equations can be obtained:

$$
\begin{gathered}
F_{1 \mathrm{x}}-F_{2 \mathrm{x}}=m_{\mathrm{c}}\left(a_{1} \sin \alpha-r_{\mathrm{cr} 1} \ddot{\beta} \sin \beta-r_{\mathrm{cr} 1} \dot{\beta}^{2} \cos \beta\right) \\
F_{1 \mathrm{y}}=m_{\mathrm{c}}\left(-a_{1} \cos \alpha+r_{\mathrm{cr} 1} \ddot{\beta} \cos \beta-r_{\mathrm{cr} 1} \dot{\beta}^{2} \sin \beta\right)+F_{2 \mathrm{y}}+m_{\mathrm{c}} g \\
F_{1 \mathrm{x}} \cdot r_{\mathrm{cr} 1} \sin \beta-F_{1 \mathrm{y}} \cdot r_{\mathrm{cr} 1} \cos \beta+F_{2 \mathrm{x}} \cdot r_{\mathrm{cr} 2} \sin \beta \\
=I_{\mathrm{c}} \ddot{\beta}+F_{2 \mathrm{y}} \cdot r_{\mathrm{cr} 2} \cos \beta
\end{gathered}
$$

$F_{1 x}, F_{1 y}$ and $F_{2 x}$ can be obtained by solving Eqs. (11)(13). In addition, the linear velocities of the crank arm and connecting rod, as well as their relative velocity $U$, can be obtained as follows:

$$
\begin{gathered}
U_{\mathrm{ca}}=r_{\mathrm{ca}} \dot{\alpha} \\
U_{\mathrm{cr}}=-r_{\mathrm{cr}} \dot{\beta} \\
U=\frac{U_{\mathrm{cr}}+U_{\mathrm{ca}}}{2}
\end{gathered}
$$

where $U_{\mathrm{ca}}$ is the linear velocity of the crank arm and $U_{\mathrm{cr}}$ is that of the connecting rod.

\subsection{Lubrication analysis}

We simulated the crank pin bearing using the hydrodynamic lubrication model assuming both surfaces to be smooth. The calculated minimum film thickness was compared with the surface roughness measured in the actual bearing to determine the presence or absence of solid-solid contact. In this study, the influence of the oil hole or grooves was not considered. In the real crank pin bearing of a slow-speed diesel engine, the lubricant is supplied at pressures ranging from 2.1 bars to 2.7 bars. The oil hole is located on the top of the bearing and the oil supply pressure is much lower than the oil film pressure. Therefore, the assumption of the boundary conditions in this study will not have a significant effect on the analysis results. Figure 3 shows a schematic of the crank pin bearing. Considering the time-dependent crank pin eccentricities, the film thickness of the lubricant, $h$, and its time rate are written as

$$
\begin{gathered}
h=c+e \cos \theta \\
\frac{\partial h}{\partial t}=\frac{\partial e}{\partial t} \cos \theta+e \frac{\partial \varphi}{\partial t} \sin \theta
\end{gathered}
$$

where $c$ is the bearing radial clearance, $e$ is the journal center eccentricity, which is the distance from the bearing center $O_{\mathrm{B}}$ to the journal center $O_{\mathrm{J}}$, and $\phi$ is the journal attitude angle. In Fig. $3, h$ is expressed in two coordinate systems $(\varphi, \mathrm{Z})$ and $(\theta, \mathrm{Z})$, both located on the bearing surface. The angular coordinate $\varphi$ has its origin on the line of $\mathrm{x}$ axis, while the coordinate $\theta$ starts from the position of maximum film thickness.

The unsteady Reynolds equation [13] is solved numerically after incorporating the time-dependent squeeze effects. The unsteady Reynolds equation in a Cartesian coordinate $\left(x=r_{\mathrm{b}} \theta, y, z\right)$ on the bearing plane is expressed as

$$
\frac{\partial}{\partial x}\left(h^{3} \frac{\partial p}{\partial x}\right)+\frac{\partial}{\partial z}\left(h^{3} \frac{\partial p}{\partial z}\right)=12 U \eta \frac{\partial h}{\partial x}+12 \eta \frac{\partial h}{\partial t}
$$

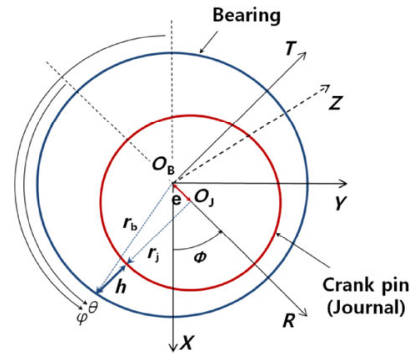

Fig. 3 Schematic diagram of a dynamic loaded crank pin bearing. 
where $p$ is the film pressure, $\eta$ is the lubricant viscosity, $U$ is the mean velocity of the journal and bearing surfaces, and $r_{\mathrm{b}}$ is the bearing radius.

As a boundary condition for the lubrication region, the following Reynolds boundary condition are used:

$$
\begin{array}{ll}
p=0 & \text { at } x_{\text {in }} \\
p=0 \text { and } \frac{\partial p}{\partial \theta}=0 & \text { at } x_{\text {out }}
\end{array}
$$

The force balance equation, which determines the eccentricity $e$ and attitude angle $\phi$, is written as

$$
\begin{aligned}
& F_{\mathrm{R}}=\int_{0}^{w} \int_{0}^{2 \pi} p \cdot \cos (\varphi+\theta) \cdot r_{b} \cdot \mathrm{d} \theta \cdot \mathrm{d} z \\
& F_{\mathrm{T}}=\int_{0}^{w} \int_{0}^{2 \pi} p \cdot \sin (\varphi+\theta) \cdot r_{b} \cdot \mathrm{d} \theta \cdot \mathrm{d} z
\end{aligned}
$$

where $w$ is the bearing width, and $F_{\mathrm{R}}$ and $F_{\mathrm{T}}$ are the radial and tangential components of the lubricant film reaction force with reference to the $(R, T)$ coordinate system, respectively. We solved the Reynolds equation with our own program using the finite difference method. The lubrication code used in this analysis has been validated in our previous paper [14].

\section{Results and discussion}

Table 1 shows the specifications of the large endconnecting rod bearing and the operation conditions used in this study. We perform the lubrication analysis for three clearance of $240 \mu \mathrm{m}, 200 \mu \mathrm{m}$, and $160 \mu \mathrm{m}$ and three lubricant temperatures of $40{ }^{\circ} \mathrm{C}, 50{ }^{\circ} \mathrm{C}$, and $60{ }^{\circ} \mathrm{C}$. The lubricating oil temperature of the crank pin bearing in the large two-stroke slow-speed diesel engine, which is the subject of this study, is measured in the range of $40^{\circ}-47^{\circ}$. Therefore, in this study, it is assumed that the lubricating oil temperature ranges between $40{ }^{\circ} \mathrm{C}$ and $60{ }^{\circ} \mathrm{C}$, to include the measurement value as the analysis condition. The absolute viscosities of the lubricant are measured as $80.27 \mathrm{cP}, 53.2 \mathrm{cP}$, and $37.22 \mathrm{cP}$ at the temperatures of $40{ }^{\circ} \mathrm{C}, 50{ }^{\circ} \mathrm{C}$, and $60{ }^{\circ} \mathrm{C}$, respectively, as shown in Fig. 4. Note that the lubricating oil temperature is assumed to be constant in this analysis. In fact, the lubricant temperature measured during the engine operation indicates a slight variation in the range of several degrees. Therefore, this analysis result may cause some errors in an actual situation.
Table 1 Specifications of the large end-connecting rod bearing and operation conditions.

\begin{tabular}{ccc}
\hline Parameters & Unit & Value \\
\hline Engine speed & $\mathrm{rpm}$ & 146 \\
Maximum gas pressure & $\mathrm{bar}$ & 177.7 \\
Piston area & $\mathrm{m}^{2}$ & 0.1233 \\
Crank pin (journal) radius, $r_{\mathrm{j}}$ & $\mathrm{m}$ & 0.260 \\
Crank arm length, $r_{\mathrm{cr}}$ & $\mathrm{m}$ & 0.885 \\
Connecting rod length, $r_{\mathrm{cd}}$ & $\mathrm{m}$ & 1.770 \\
Crank pin bearing width, $w$ & $\mathrm{~m}$ & 0.165 \\
Piston mass, $m_{\mathrm{p}}$ & $\mathrm{kg}$ & 589.1 \\
Connecting rod mass, $m_{\mathrm{c}}$ & $\mathrm{kg}$ & 865.93 \\
Moment of inertia of connecting rod, $I_{\mathrm{c}}$ & $\mathrm{kg} \cdot \mathrm{m}^{2}$ & 28.1 \\
Absolute viscosities at $40,50,60{ }^{\circ} \mathrm{C}$ & $\mathrm{cP}$ & $80.27,53.2$, \\
& & 37.22 \\
Lubricant temperature & ${ }^{\circ} \mathrm{C}$ & $40,50,60$ \\
Clearance, c & $\mu \mathrm{m}$ & $240,200,160$ \\
\hline
\end{tabular}

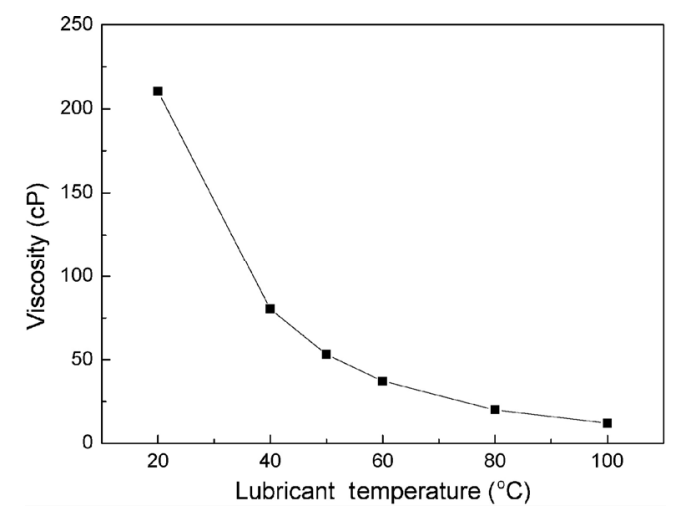

Fig. 4 Measured viscosity of lubricant with a temperature.

However, the results are meaningful in terms of being able to manage the critical temperature value of the lubricant which does not cause solid-solid contact.

We calculate the bearing loads and lubricant velocity by conducting motion analysis of the crank pin system to evaluate the lubrication state of the crank pin bearing. The piston gas pressure with crank angle under full load is measured from the marine two-stroke diesel engine as shown in Fig. 5. The maximum gas pressure is 177.7 bar at a crank angle of $13^{\circ}$. The crank pin bearing loads are calculated from the gas pressure and inertial force of the piston and the connecting rod. The calculated crank pin bearing loads in the radial and tangential directions with crank angle are demonstrated in Fig. 6(a). The maximum radial force is $1820.7 \mathrm{kN}$ at a crank angle of $13^{\circ}$, which corresponds 


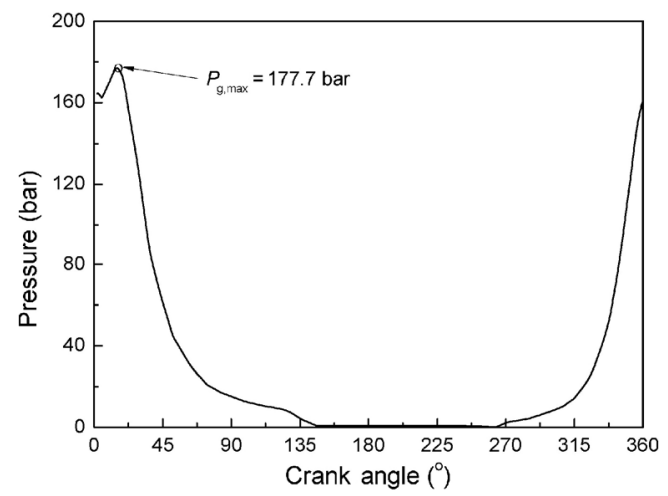

Fig. 5 Piston gas pressure with crank angle.

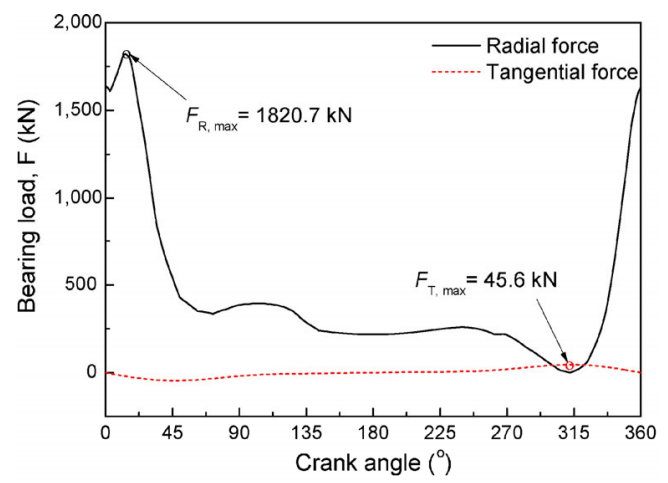

(a) Radial and tangential forces of crank pin bearing

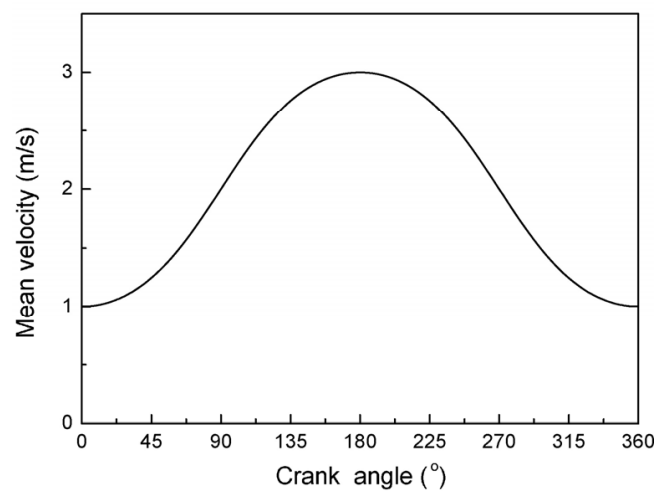

(b) Mean relative velocity of crank pin and bearing

Fig. 6 Internal loads of crank pin bearing and mean relative velocity of crank pin and bearing with crank angle.

to an upward movement of the piston, while the maximum tangential force is $45.7 \mathrm{kN}$ at a crank angle of $313^{\circ}$ which corresponds to a downward motion. Figure $6(\mathrm{~b})$ shows the mean relative velocity of the crank pin bearing with crank angle using Eqs. (14) (16). The mean relative velocity is applied as a lubricant velocity in the lubrication analysis.

Figure 7 shows the orbital path of the crank pin bearing for a clearance of $240 \mu \mathrm{m}$ and a lubricant temperature of $40{ }^{\circ} \mathrm{C}$. It is shown that the largest eccentricity occurs at a crank angle is $19^{\circ}$, while the smallest eccentricity occurs at a crank angle of $325^{\circ}$. Figure 8 shows that 3D pressure and film thickness distributions at the crank angle of $19^{\circ}$ for the crank pin bearing for the clearance of $240 \mu \mathrm{m}$ and lubricant temperature of $40^{\circ} \mathrm{C}$.

Figure 9 shows the variations in film pressure and thickness with the crank angles for the crank pin bearing for the three clearances at the lubricant

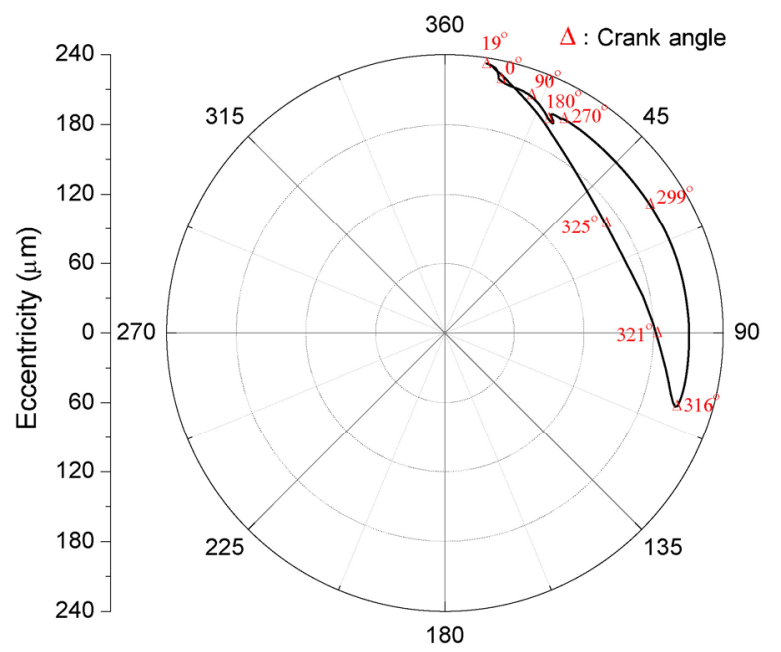

Fig. 7 Orbital path of the crank pin bearing with a clearance of $240 \mu \mathrm{m}$ and a lubricant temperature of $40{ }^{\circ} \mathrm{C}$.
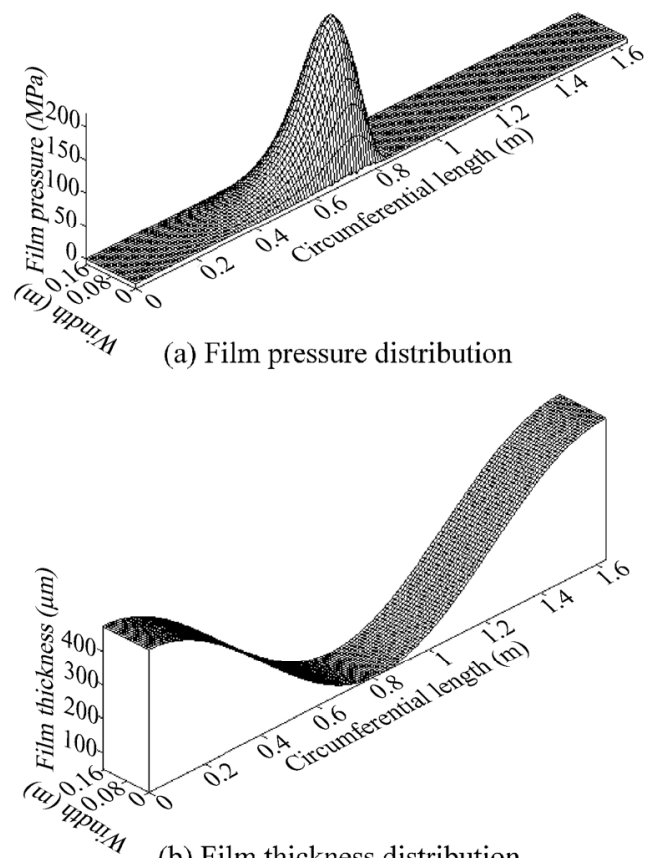

(b) Film thickness distribution

Fig. 8 3D pressure and film thickness distributions at the crank angle of $19^{\circ}$ for the crank pin bearing with a clearance of $240 \mu \mathrm{m}$ and a lubricant temperature of $40{ }^{\circ} \mathrm{C}$. 


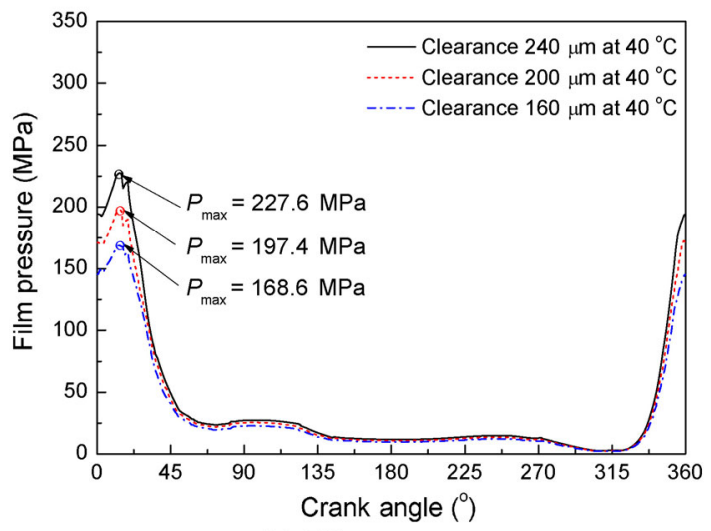

(a) Film pressure

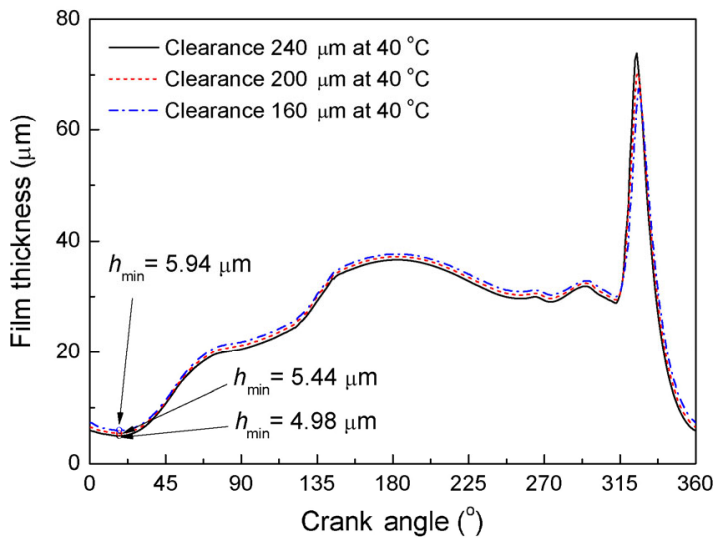

(b) Film thickness

Fig. 9 Pressure and film thickness with the crank angles for the crank pin bearing with three different clearances and a lubricant temperature of $40{ }^{\circ} \mathrm{C}$.

temperature of $40{ }^{\circ} \mathrm{C}$. As shown in Fig. 9(a), the film pressure decreases with a decrease in clearance, and the maximum film pressures for the clearances of $240 \mu \mathrm{m}, 200 \mu \mathrm{m}$, and $160 \mu \mathrm{m}$ are 227.6 MPa, 197.4 MPa, and $168.6 \mathrm{MPa}$, respectively. The film thickness increases with a decrease in clearance, and the minimum film thicknesses for the three clearances are calculated as $4.98 \mu \mathrm{m}, 5.44 \mu \mathrm{m}$, and $5.94 \mu \mathrm{m}$, respectively.

The variations in film pressure and thickness for the crank pin bearing for a clearance of $240 \mu \mathrm{m}$ at three lubricant temperatures are investigated in Fig. 10. It is shown that a higher lubricant temperature gives higher film pressure and lower film thickness. The maximum film pressures for the lubricant temperatures of $40{ }^{\circ} \mathrm{C}, 50{ }^{\circ} \mathrm{C}$, and $60^{\circ} \mathrm{C}$ are calculated as $227.6 \mathrm{MPa}$, $269.6 \mathrm{MPa}$, and $309.2 \mathrm{MPa}$, and the minimum film thicknesses are calculated as $4.98 \mu \mathrm{m}, 3.46 \mu \mathrm{m}$, and $2.41 \mu \mathrm{m}$, respectively. Note that the effect of lubricant temperature on the film pressure and thickness is

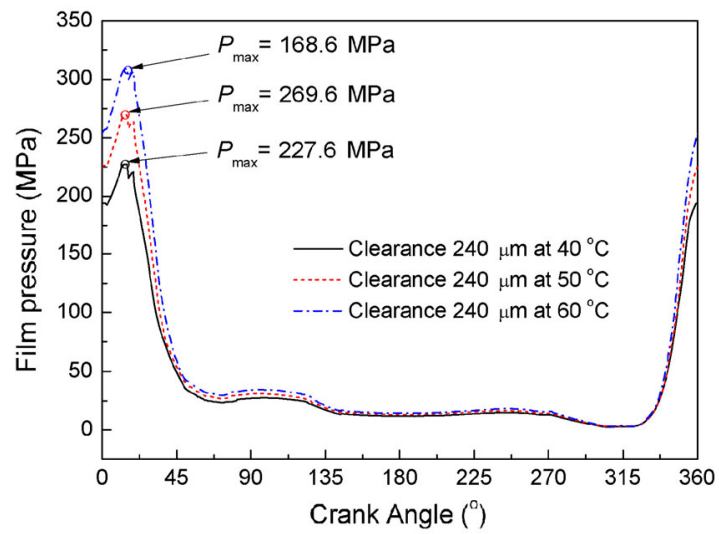

(a) Film pressure

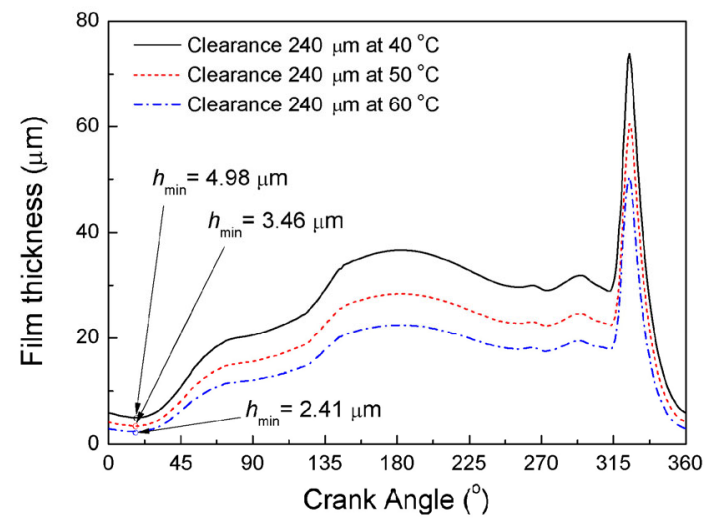

(b) Film thickness

Fig. 10 Pressure and film thickness with the crank angles for the crank pin bearing with a clearance of $240 \mu \mathrm{m}$ at three different lubricant temperatures.

higher than that of clearance. Compared to the variations in film thickness for the clearance shown in Fig. 9(b), the film thickness in Fig. 10(b) decreases significantly with an increase in lubricant temperature. This tendency can be seen in more detail in Fig. 11, which summarizes of the minimum film thickness at three lubricant temperatures for the crank pin bearing for three clearances. It is found that the lubricant temperature has a larger effect on the minimum film thickness.

In addition, we evaluate the lubricant film parameter, $\Lambda$ of the crank pin journal and bearing to observe the failure possibility of the crank pin. The lubricant film parameter is defined as $\Lambda=h_{\min } / \sigma=h_{\min } /$ $\sqrt{R_{\mathrm{q} 1}^{2}+R_{\mathrm{q} 2}^{2}}$, where $\sigma$ is the composite standard deviation of surface heights of the two surfaces, and $R_{\mathrm{q} 1}$ and $R_{\mathrm{q} 2}$ are the root mean square roughnesses of the two surfaces $[15,16]$. Generally, if the average 


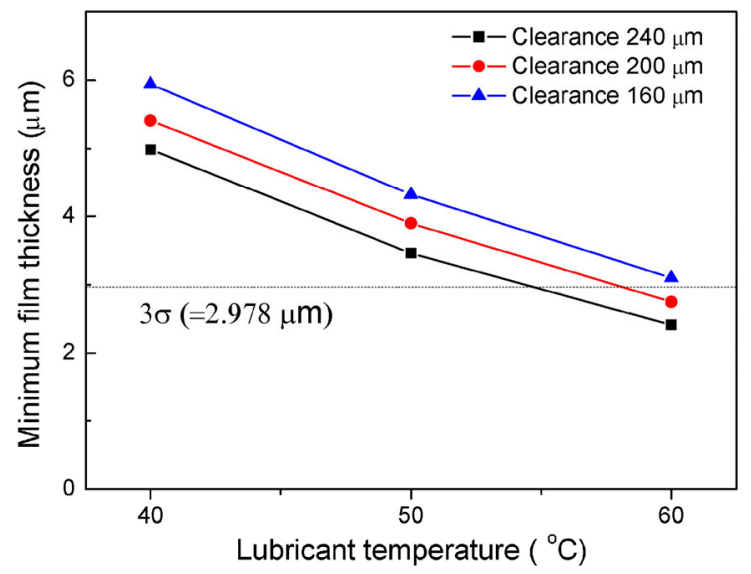

Fig. 11 Minimum film thickness with three different lubricant temperatures for the crank pin bearing with three different clearances.

film thickness is less than three times the composite surface roughness, the surface asperities will force direct solid-solid contact $[15,17]$. In this study, we measure the surface roughness of the crank pin journal and bearing. The measured $R_{\mathrm{q} 1}$ and $R_{\mathrm{q} 2}$ are $0.445 \mu \mathrm{m}$ and $0.887 \mu \mathrm{m}$, respectively, which leads to $3 \sigma=2.978 \mu \mathrm{m}$. The line of $3 \sigma$ is also marked in Fig. 11. It is estimated that the minimum film thicknesses of the cases for the clearances of $200 \mu \mathrm{m}$ and $160 \mu \mathrm{m}$ at the lubricant temperature of $60{ }^{\circ} \mathrm{C}$ are less than $3 \sigma$, resulting in solid-solid contact, which can cause the failure of the crank pin. It is concluded that a lubricant temperature of less than $50{ }^{\circ} \mathrm{C}$ is required to prevent solid-solid contact. Confirmatory experiments for the effects of surface roughness and lubricant temperature are underway for the diesel engine, and we expect to obtain good results in the near future.

\section{Conclusions}

In this study, to investigate an adhesional failure on the crank pin bearing of a marine two-strokes diesel engine, a lubrication analysis was conducted on crank pin journal and bearing. Through the motion analysis of the piston-connecting rod-crank arm system, the bearing loads and lubricant velocity were calculated. Then, the lubrication analysis for three clearance of $240 \mu \mathrm{m}, 200 \mu \mathrm{m}$, and $160 \mu \mathrm{m}$ at three lubricant temperatures of $40{ }^{\circ} \mathrm{C}, 50{ }^{\circ} \mathrm{C}$, and $60{ }^{\circ} \mathrm{C}$ was performed. The results showed that the maximum film pressure decreased with decreasing clearance and lubricant temperature, and that film thickness increased with decreasing clearance and lubricant temperature. The lubricant temperature had a higher effect on the film pressure and film thickness than the clearance. In the evaluation of the lubricant film parameter, the minimum film thicknesses of the cases for the clearances of $200 \mu \mathrm{m}$ and $160 \mu \mathrm{m}$ at the lubricant temperature of $60{ }^{\circ} \mathrm{C}$ were estimated to be less than $3 \sigma$, which resulted in solid-solid contact of the crank pin bearing. In addition, we concluded that the management of the clearance is important to prevent solid-solid contact, but the operation of the crank pin bearing at a lubricant temperature of less than $50{ }^{\circ} \mathrm{C}$ is more desirable for a sufficiently lubricated film.

\section{Acknowledgement}

This work was supported by the Pukyong National University Research Abroad Fund in 2015 (C-D-20150500)

Open Access: The articles published in this journal are distributed under the terms of the Creative Commons Attribution 4.0 International License (http:// creativecommons.org/licenses/by/4.0/), which permits unrestricted use, distribution, and reproduction in any medium, provided you give appropriate credit to the original author(s) and the source, provide a link to the Creative Commons license, and indicate if changes were made.

\section{References}

[1] Booker J F. Dynamically loaded journal bearings: Mobility method of solution. J Basic Eng 87(3): 537-546 (1965)

[2] Booker J F. Dynamically-loaded journal bearings: Numerical application of the mobility method. J Lubr Technol 93(1): 168-176 (1971)

[3] Cho M R, Han D C, Choi J K. Oil film thickness in engine connecting-rod bearing with consideration of thermal effects: Comparison between theory and experiment. J Tribol 121(4): 901-907 (1999)

[4] Fantino B, Frêne J. Comparison of dynamic behavior of elastic connecting-rod bearing in both petrol and diesel engines. J Tribol 107(1): 87-91 (1985)

[5] Goenka P K. Dynamically loaded journal bearings: Finite element method analysis. J Tribol 106(4): 429-439 (1984) 
[6] Aitken M B, McCallion H. Elastohydrodynamic lubrication of big-end bearings. Part 1. Theory. Proc Inst Mech Eng Part C J Mech Eng Sci 205(2): 99-106 (1991)

[7] LaBouff G A, Booker J F. Dynamically loaded journal bearings: A finite element treatment for rigid and elastic surfaces. J Tribol 107(4): 505-513 (1985)

[8] Rebora A U, Stefani F A. Elastohydrodynamic analysis of connecting rod bearing for high performance engines: Structural inertia effect. In Proceedings of the 3rd AIMETA International Tribology Conference, Salerno, Italy, 2002.

[9] Krasser J, Laback O, Loibnegger B, Priebsch H H. A calculation method for crank train bearings considering pressure and temperature dependent oil viscosity. In Proceedings of the SIA 3rd International Congress, Paris, 1996.

[10] Kim B J, Kim K W. Thermo-elastohydrodynamic analysis of connecting rod bearing in internal combustion engine. $J$ Tribol 123(3): 444-454 (2001)

[11] Bukovnik N, Dörr V, Čaika V, Bartz W J, Loibnegger B. Analysis of diverse simulation models for combustion engine journal bearings and the influence of oil condition. Tribol Int 39(8): 820-826 (2006)

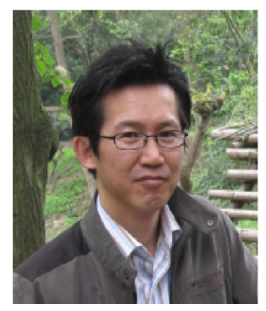

Suk Man MOON. He received his master degree in mechanical engineering in 1999 from Pusan National University, Korea. He is

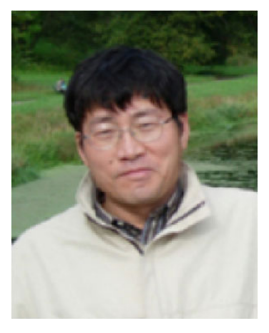

Yong Joo CHO. He received his Ph.D. degree in mechanical engineering from Korea Advanced Institute of Science and Technology, Korea in 1994. He has worked in

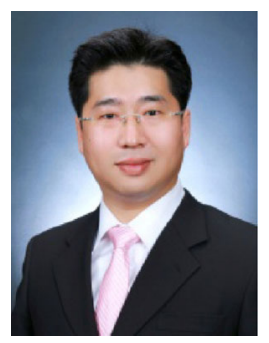

Tae Wan KIM. He received his Ph.D. degree in mechanical engineering from Pusan National University, Korea in 2002. He has worked in Pukyong National
[12] Wu Q L, Duan S L, Wu Z H, Xing H. Lubrication study on a connecting rod big end bearing of two-stroke marine diesel engine. In Proceedings of the 3rd International Conference on Computer Application and System Modeling, Taiyuan, China, 2010: 184-188.

[13] Hamrock B J, Schmid S R, Jacobson B O. Fundamentals of Fluid Film Lubrication. 2nd ed. New York (USA): Marcel Dekker, 2004.

[14] Kim T W, Cho Y J. The flow factors considering the elastic deformation for the rough surface with a non-Gaussian height distribution. Tribol Trans 51(2): 213-220 (2008)

[15] Bhushan B. Handbook of Micro/Nanotribology. Boca Raton (USA): CRC Press, 1999.

[16] Greenwood J A, Tripp J H. The contact of two nominally flat rough surfaces. Proc Inst Mech Eng 185(1): 625-634 (1970)

[17] Teodorescu M, Kushwaha M, Rahnejat H, Rothberg S J. Multi-physics analysis of valve train systems: from system level to microscale interactions. Proc Inst Mech Eng Part K J Multi-Body Dyn 221(3): 349-361 (2007)

a Ph.D. student in the Tribology Laboratory at the same university. His research areas cover surface engineering, lubrication, friction and wear for engine.

Pusan National University since 1979. His current position is a professor of mechanical engineering department and the director of the Tribology Laboratory. His research areas cover surface topology, gear lubrication, and friction and wear for mechanical device.

University since 2008. His current position is a professor of mechanical engineering department and the director of the Nanotribology Laboratory. His research areas cover surface modification, lubrication, friction and biomimetic engineering. 